\title{
5 Zeichen und Abkürzungen
}

// doppelter Schrägstrich: trennt die Antonyme (kurz//lang)

○ $\quad$ kleiner Kreis: trennt die Beispiele bzw. Beispiele von der Erklärung

* $\quad$ vor dem Wort: kennzeichnet ein nur erfundenes Wort zu einem paradoxen Paar

[ ] eckige Klammern: koppeln unterschiedliche Formen: Jäger[in], Gejagte[r], oder stehen innerhalb einer runden Klammer als weglassbare Erläuterung o. Ä.: z. B. Störschall (bei Hörgeräten: die nicht gewünschten Nebengeräusche [Straßenlärm, diffuse Geräusche im Restaurant usw.], die man nicht hören will)

( ) runde Klammern: enthalten Angaben zu Bedeutung, Fachbereich, Stil, landschaftlichem Gebrauch und Erläuterungen; stehen im Zitat der Belege, z. B. (Medizin); (Der Spiegel 7. 4. 2018)

$\uparrow \quad$ siehe: findet sich bei Verweiswörtern: einsetzen $\uparrow$ als Erben einsetzen

个auch: (weist am Schluss eines Antonymenpaares auf Wörter hin, die inhaltlich mit dem zweiten Wort zusammenhängen: einschalten//ausschalten; 个auch: abschalten, auslassen, ausmachen; Ehemann//Ehefrau; $\uparrow a u c h$ Gattin) 